Oosterveld-Vlug, M.G., Francke, A.L., Pasman, H.R., Onwuteaka-Philipsen, B.D. How should realism and hope be combined in physician-patient communication at the end of life? An online focus-group study among participants with and without a Muslim background. Palliative \& Supportive Care: 2016

\begin{tabular}{|l|l|}
\hline $\begin{array}{l}\text { Postprint } \\
\text { Version }\end{array}$ & 1.0 \\
\hline Journal website & https://doi.org/10.1017/S1478951516000833 \\
\hline Pubmed link & $\underline{\text { https://www.ncbi.n/m.nih.gov/pubmed/?term=27819209 }}$ \\
\hline DOI & $10.1017 /$ S1478951516000833 \\
\hline
\end{tabular}

This is a NIVEL certified Post Print, more info at http://www.nivel.eu

\title{
How should realism and hope be combined in physician-patient communication at the end of life? An online focus-group study among participants with and without a Muslim background.
}

MARISKA G. OOSTERVELD-VLUG, PH.D., ${ }^{1}$ ANNEKE L. FRANCKE, PH.D., ${ }^{1,2} \mathrm{H}$. ROELINE W. PASMAN, PH.D., ${ }^{1}$ AND BREGJE D. ONWUTEAKA-PHILIPSEN, PH.D. ${ }^{1}$

${ }^{1}$ Department of Public and Occupational Health, EMGO Institute for Health and Care Research, Expertise Center for Palliative Care, Vrije Universiteit Medical Center, Amsterdam, The Netherlands.

${ }^{2}$ Netherlands Institute for Health Services Research, Utrecht, The Netherlands.

\begin{abstract}
Objective: Maintaining false hope may result in prolonged curative aggressive treatments until the very last stage of life. In this study, we sought to explore how people think that realistic and hopeful information should best be combined in physician-patient communications at the end of life.

Method: During a period of 15 days, participants of five online focus groups (OFGs) could log in onto a closed discussion site and offer responses to several topics. Avariety of people participated: patients, older people, relatives, and healthcare professionals with and without a Muslim background. Participants with a Muslim background constituted a separate group, because previous research indicated that theymight have distinct views on good end-of-life care and communication. Transcripts were analyzed following the principles of thematic analysis.

Results: Participants from all focus groups preferred that physicians provide realistic information in an empathic way, stating that the patient would never be left on his own and that withholding curative treatment was not equal to withholding care, explicitly asking how the patient could be helped during the time remaining, and involving other professionals in the care process and communications. As such, physicians could support patients' transition from "hope for a cure" to "hope for a good death." Muslims specified the way they wished to receive realistic information: first from a relative, and not by using the
\end{abstract}


Oosterveld-Vlug, M.G., Francke, A.L., Pasman, H.R., Onwuteaka-Philipsen, B.D. How should realism and hope be combined in physician-patient communication at the end of life? An online focus-group study among participants with and without a Muslim background. Palliative \& Supportive Care: 2016

term "incurable illness," but rather by informing the patient that they had no remaining curative treatments available.

Significance of results: Realism and hope are not necessarily mutually exclusive and can be combined when providing realistic information in a delicate and culturally sensitive way. This study provides suggestions on how physicians can do so. Communication skills training as well as anchoring knowledge of the diversity of cultural and religious views into physicians' education could improve end-of-life communication.

\section{INTRODUCTION.}

Due to technological developments in medicine and the numerous treatments that are now possible, patients, relatives, and physicians often have high expectations and hopes when a patient becomes seriously ill. However, these high expectations may result in curative overtreatment, which many participants in one questionnaire study labeled as "inappropriate end-of-life care" (KNMG, 2015). Receiving overly aggressive treatments toward the end of life can cause patients to suffer from serious side effects and decreased physical function, and can hamper advance care planning (ACP) conversations and prevent a peaceful death (Buiting et al., 2011; Mattes \& Sloane, 2015).

The wish to remain optimistic and hopeful has been found to play an important role in curative overtreatment (Mattes \& Sloane, 2015). Research shows that the majority of patients with an incurable illness or terminal cancer still hope for a cure or life prolongation, even against all odds (Clayton et al., 2005; Benzein et al., 2001; Weeks et al., 2012; Chen et al., 2013). They sometimes present themselves more physically and mentally fit than they actually feel, hoping to receive another treatment (Buiting et al., 2011). In turn, physiciansmay notwant to disappoint patients who explicitly wish for treatment by taking away their last hopes. As such, a so-called coalition of hope (de Haes \& Koedoot, 2003) can come into existence, in which patients and physicians mutually reinforce each other's attitudes of not giving up (Buiting et al., 2011).

That many patients hope for a cure even when they are in the last phase of life suggests that physicians must choose between providing hopeful or realistic information (Back et al., 2003; van Vliet, 2013). Additionally, the ethics of hope have often been understood as a conflict between duties: do not lie versus do not destroy hope (Olver, 2005).

Such a way of framing the ethics of hope may easily place physicians on the side of realism and patients on the side of (false) hope (Olsman et al., 2015).

However, hoping for a cure and preparing for potential death need not be mutually exclusive (Back et al., 2003), as, for example, shown in an interview study among advanced lung cancer patients and their family members in which ACP did not interfere with hope for a cure, and vice versa (Robinson, 2012). However, in practice, a substantial proportion of physicians seem to feel differently. Another study showed that oncological specialists considered discussing death or dying while simultaneously administering chemotherapy a contradiction, which could negatively affect a patient's well-being by taking away their hope (Buiting et al., 2011). Indeed, hope has been described as an essential element of human life, one that is integral to 
Oosterveld-Vlug, M.G., Francke, A.L., Pasman, H.R., Onwuteaka-Philipsen, B.D. How should realism and hope be combined in physician-patient communication at the end of life? An online focus-group study among participants with and without a Muslim background. Palliative \& 1 Supportive Care: 2016

a person's quality of life and well-being (Rustoen, 1995; Lin \& Bauer- Wu, 2004; Clayton et al., 2005; McClement \& Chochinov, 2008).

As shown above, the relationship between hopeful and realistic information is rather complex. For some patients, realistic information can nurture hope, while others argue that realistic information destroys hope (Hagerty et al., 2005). However, the work of van Vliet and colleagues (2013) showed that a need for hope and realism might not be as conflicting as often thought and that the crux of the matter seems to lie in providing "realistic hope." Other studies suggest that physicians must possess the skill of balancing hope with honesty (Clayton et al., 2008).

However, how to combine realistic and hopeful information in communicating with patients is barely explored.

Moreover, the few studies conducted relate almost exclusively to cancer patients (Clayton et al., 2008), for whom "maintaining hope" has been found to be more important than for patients with other life-threatening illnesses like COPD and AIDS (Curtis et al. 2002). In addition, earlier studies failed to include people with a Muslim background.

Because their number is increasing inWestern countries, and because studies have shown that their preferences when it comes to end-of-life communication differs from that of non-Muslims (e.g., relatives are often quite influential in end-of-life communication and sometimes choose to not confront the patient with a poor prognosis), it is important to include this often-unexplored group (Hagerty et al., 2005; Clayton et al., 2008; de Graaff et al., 2010).

Therefore, the aim of our study was to explore how Dutch patients, older people, relatives, and healthcare professionals with and without a Muslim background think that realistic and hopeful information should be combined in physician-patient communication at the end of life. The study was part of a larger research project focusing on the causes and potential solutions for curative overtreatment, requested by the Koninklijke Nederlandsche Maatschappij tot bevordering der Geneeskunst (the Royal Dutch Medical Association) (KNMG, 2015).

\section{METHODS.}

\section{Design.}

Five online focus groups (OFGs) were organized in the autumn of 2014. During a period of 15 days, participants could log on to a closed discussion site and react at any time of the day, not necessarily when anyone else was participating. Organizing focus groups online has the advantage that participants can easily join the discussion from their homes at a convenient time. Moreover, previous research has indicated that the anonymity of OFGs allows participants to express themselves more freely, particularly regarding sensitive topics (Tates et al., 2009; Zwaanswijk \& van Dulmen, 2014).

\section{[TABLE 1].}

\section{Participants and Sampling}

Three different groups of people participated separately from each other, so that they could freely express their views and experiences: (1) patients, older people, and relatives without a Muslim background (24 participants divided over two OFGs); (2) healthcare professionals without a Muslim background (21 participants divided over 
Oosterveld-Vlug, M.G., Francke, A.L., Pasman, H.R., Onwuteaka-Philipsen, B.D. How should realism and hope be combined in physician-patient communication at the end of life? An online focus-group study among participants with and without a Muslim background. Palliative \& 1 Supportive Care: 2016

two OFGs); and (3) patients and relatives with a Muslim background ( 9 participants in one OFG) (see Table 1 for their characteristics). Muslims living in The Netherlands are often first- or second-generation migrants from former Dutch colonies like Surinam and Indonesia, or (children of) laborers from Morocco or Turkey.

Because previous research has indicated that Muslims might have distinct views on what constitutes good care and communication at the end of life, related to their cultural and religious background, we chose to have a specific group for Muslim participants.

The majority of the participants in groups 1 and 2 were recruited by means of a 2013 online questionnaire study among patients, older people, relatives, and healthcare professionals regarding (in)appropriate care in the last phase of life (KNMG, 2015). In that study, respondents could write down their email address if they were interested in participating in a follow- up study. In selecting participants for the OFGs, we aimed to create a sample of people with awide range of characteristics (sex, age, religion, region, organization through which they received the questionnaire in 2013, and healthcare professionals' occupation), so as to potentially maximize the views on hope and realism expressed inthe focus groups. Because older people and Muslims were underrepresented in the questionnaire study, we recruited some extra participants with help from the Association of Catholic Organizations of Senior Citizens in the Netherlands (Unie KBO) and the Network of Organizations for Older Migrants (NOOM). Subsequently, the selected people received an emailwith information on the aim, content, and procedure of the study and were invited to participate.

\section{PROCEDURE AND TOPICS.}

Those who agreed to participate received a link to the closed discussion site and a personal login code and password. To ensure anonymity, participants were asked not to mention their names or addresses or the names of their healthcare providers. Every two days (except for weekends), a new topic was introduced with a new first question, and participants were informed about this via email and encouraged to respond. The days in betweenwere used to introduce a follow-up question. The first author (MOV) functioned as the moderator in group discussions and tried to facilitate discussions by summarizing reactions, asking additional questions to clarify participants' views if necessary, and encouraging participants to react to others' comments. After a week, a reminder email was sent to participants who had not yet reacted.

Topics were based on literature research, an expert meeting, and the findings from the earlier-mentioned questionnaire study on "(in)appropriate care in the last phase of life" conducted in 2013 (KNMG, 2015), and were deemed to require more-detailed exploration.

Apart from "hope and realism," the other topics were "timely discussion of care needs and possibilities," "communication among physician, patient, and relatives," "societal views on death," and "consultation and coordination between healthcare professionals." Healthcare professionals were presented an extra topic: "organization of the Dutch healthcare system." For the present article, reactions within the topic "hope and realism" were most relevant, although we did not solely use the reactions to this topic, as reactions to other themes offered interesting insights. 
Oosterveld-Vlug, M.G., Francke, A.L., Pasman, H.R., Onwuteaka-Philipsen, B.D. How should realism and hope be combined in physician-patient communication at the end of life? An online focus-group study among participants with and without a Muslim background. Palliative \& 1 Supportive Care: 2016

\section{Hope and Realism.}

The topic "hope and realism" was introduced as follows:

Healthcare professionals, patients, and relatives may unintentionally stimulate each other to continue with medical treatments. Physicians often prefer not to start discussing withholding or withdrawing a treatment, because they do not want to take away patients' hope for a cure or life prolongation.

In turn, patients sometimes present themselves more optimistically (about their physical and mental state) than they actually feel, hoping to receive another treatment.

\section{Questions.}

1. Do you recognize this? Do you think that providing "hopeful information" should be replaced by providing "realistic information"? If no, why not? If yes, how should realistic information preferably be delivered?

2. Are there other ways for physicians to provide hope while simultaneously being realistic?

\section{Analysis.}

The first available data (from the first two OFGs) were discussed by MOV and AF, who decided that no rephrasing of questions or topics was needed for the remaining three OFGs. Transcripts were analyzed following the principles of thematic analysis (Boyatzis, 1998). Transcripts were read and reread to allow the researchers to become thoroughly familiar with the data. Codes were then ascribed to meaningful text units (e.g., communicating with empathy, shift of hopes, involvement of other professionals).

Codes were grouped together, and we searched for themes and their interrelatedness. After coding several interviews in this inductivemanner, the findings were discussed with different members of the research group, all experienced in qualitative research, and we worked toward a consensus about interpretation of the key themes. MOV checked these interpretations with the existing data. A professional translated the quotes that we eventually chose to illustrate our results (shown in Tables 2-4).

\section{Ethics.}

The anonymity of participants was strictly safeguarded throughout the process of data collection and analysis. Ethical approval for this study was not needed under the applicable Dutch legislation, since all participants were competent individuals and the study did not involve any interventions or treatments.

\section{RESULTS.}

\section{Circle of Hope.}

Participants from all OFGs recognized that physicians and patients often encourage each other to continue with medical treatments and as such reinforce each other's hopes (quotes 1 and 2). Although a few participants indicated that the maintenance of hope could foster optimism, the majority regarded such a "circle of hope" as undesirable. Applying treatment after treatment when the chances for a cure are very small was evaluated as nurturing false hope. 
Oosterveld-Vlug, M.G., Francke, A.L., Pasman, H.R., Onwuteaka-Philipsen, B.D. How should realism and hope be combined in physician-patient communication at the end of life? An online focus-group study among participants with and without a Muslim background. Palliative \& 1 Supportive Care: 2016

Aside from being a waste of resources, participants mentioned that it often heavily burdens patients and deprives them of a dignified last phase of life, where they could say goodbye to their loved ones and complete unfinished business.

Several factors explaining this circle of hope were raised related to either patients, relatives, or physicians.

For example, participants described how some patients wish to start any treatment no matter how small the chances for cure or life prolongation are. Their urge to survive and their faith in medicine can cause them to listen selectively to a physician's message (quote 3). Participants also reported that some patients feel morally obliged toward society to fight against their disease and not allow themselves to be defeated by it. In addition, relativeswere thought to play a role here: they can sometimes not accept that the patient is incurably ill and push him/her to undergo just one more treatment (quote 4). Another factor mentioned by participants was that physicians are not always clear in their communications. For example, they present some new treatment alternatives right after talking about the patient being incurably ill. In fact, according to some participants, unfamiliarity with palliative treatment possibilities as well as the hope physicians have themselves make them reluctant towithhold or withdraw treatments with a curative aim. Because physicians are taught to cure the sick, it may feel like a failure when they cannot meet the high expectations that patients have, especially when the physician and patient know each other for a longer period of time (quote 5).

\section{[TABLE 2].}

In addition, participants with a Muslim background tended to recognize the existence of a circle of hope. And, in line with other participants, they regarded it as unacceptable when physicians consciously gave false hope by providing unrealistic information or withholding realistic information.

However, hope was found to play a different role for Muslims than for non-Muslims. They pointed out that they always keep their hopes up and rely on their faith in Allah, who is the decider when it comes to life and death. Moreover,Muslims reported that they are obliged to seek all possibilities for cure (quotes 6 and 7). The terms "curative overtreatment" and "life prolongation" were therefore not appropriate for people with a Muslim background.

\section{Combining Hopeful and Realistic Information.}

The majority of participants from all OFGs - those with and without a Muslim background - reported that they prefer physicians to give realistic information rather than unrealistic but hopeful information (quotes 8 and 9).

Several participants detailed some conditions under which this realistic information could best be provided.

First, realistic information should be provided at the right moment, that is, when the patient and family are open to receiving this information and are in the "right" state of mind. Second, realistic information must not be provided too bluntly, but rather with empathy. Delivering bad news in a fiveminute conversation or by providing a pamphlet was seen as inconsiderate. Instead, participants indicated that physicians must possess good communication skills, so that they can communicate with the patient and his/her family in a clear, honest, and empathic manner (quote 10). Quote 10 reflects what many more participants from all groups reported: that it is not a 
Oosterveld-Vlug, M.G., Francke, A.L., Pasman, H.R., Onwuteaka-Philipsen, B.D. How should realism and hope be combined in physician-patient communication at the end of life? An online focus-group study among participants with and without a Muslim background. Palliative \& Supportive Care: 2016

matter of providing either realistic information or hopeful information, but that they should go together (quotes 11 and 12).

\section{[TABLE 3].}

Most participants with a Muslim background preferred that physicians provide realistic information to relatives first. Thereafter, open and explicit communication with the patient does not always occur.

Muslims reported that family members, especially of first-generation immigrant patients, sometimes choose to not confront the patient with his/her poor prognosis and the fact that they are nearing death (quote 13). In addition, Muslim participants detailed how a physician could best communicate that a patient is nearing death: they should inform the patient and/or relatives that they have no curative treatments available, but they should never state that a patient has an "incurable illness," because physicians are not the ones who decide the question of life and death (quote 14).

\section{[TABLE 4].}

\section{Shifting of Hope.}

When the end of life approaches and there is, from a medical perspective, no longer a chance for a cure, participants described how hope for a cure gradually shifted to other goals - like hope for a good death and a good rounding-off of life. In this phase, participants emphasized the importance of physicians telling their patients that they would never leave him/her on his own and that having no curative treatment available was not equal to withholding care. Participants also wanted physicians to explicitly ask how they might support the patient during the time remaining (quote 15 ). As such, physicians could support the transition patients need to make from "hope for a cure" to "hope for a good death" (quote 16).

According to several participants, physicians could more often involve and consult specialized palliative care teams, psychologists, or social workers in order to help them regard palliative care as a "hopeful" form of care as well (quote 17).

Some participants also reported that physicians couldmore often refer patients to people who could provide "hope," that is, spiritual counselors, pastors, or imams (quote 18). Muslim participants especially expressed a preference to involve animamwhen the patientwas aware ofhis/her terminal illness. Both participants with a Muslim background and healthcare professionals treating Muslim patients recommended involving aMuslim spiritual counselor to facilitate clarity in end-oflife communications (quote 19).

\section{DISCUSSION.}

By conducting five OFGs, this study investigated, from different perspectives, howrealistic and hopeful information should best be combined in physician-patient communications at the end of life. Our results show that participants from all groups preferred that physicians provide realistic information on diagnosis and prognosis in an empathic way, by assuring that the patient would be accompanied throughout the last stage of their life by the physicians themselves and by other professionals. Our finding that participants preferred realistic information over unrealistic but hopeful information is in line with other studies (Clayton et al., 2005; Hagerty et al., 2005; 
Oosterveld-Vlug, M.G., Francke, A.L., Pasman, H.R., Onwuteaka-Philipsen, B.D. How should realism and hope be combined in physician-patient communication at the end of life? An online focus-group study among participants with and without a Muslim background. Palliative \& 1 Supportive Care: 2016

Clayton et al., 2008; van Vliet et al., 2013). In a survey study among cancer patients, no less than $98 \%$ of patients wanted their doctor to be realistic, to provide an opportunity to ask questions, and to acknowledge them as individuals when discussing prognosis (Hagerty et al., 2005). They perceived that provision of realistic information in a supportive and collaborative environment was more nurturing of hope than avoidant behavior (Hagerty et al., 2005). In addition, the systematic review of Clayton et al. (2008) highlighted the need for health professionals to balance honesty with hope without encouraging unrealistic expectations of longevity in the context of a far-advanced life-limiting illness. However, whereas previous studies focused almost exclusively on cancer patients, our findings apply to a wide variety of participants, who have experiences with all kinds of life-limiting diseases, with and without a professional view, and with and without aMuslim background.

The strategies for fostering hope when discussing prognosis that are recommended based on the review conducted by Clayton et al. (2008) are very similar to what the participants in our study suggested: be honest and open without being blunt; offer reassurance that the patient will be supported throughout the illness trajectory; and reassure them that many treatments are available for controlling pain and other symptoms. Nevertheless, some patients might need a more direct or indirect approach, as was concluded from a study that found high variability in the way patients personally process the interaction of hope and prognostic information (Curtis et al., 2008).

Our participants indicated that the transition patients and family (and sometimes also physicians) need to make from "hope for a cure" to "hope for a good death" is best supported when realistic information, realistic hope, and empathy are combined well for the individual patient. Additionally, previous studies have described and illustrated such a transition and a reframing of hope when death comes nearer (Benzein et al., 2001; Clayton et al., 2005; Pattison \& Lee, 2011; van Vliet, 2013). It thus seems that the way information is delivered to patients and families is often as important as the content.Displaying empathy and acquiring understanding are important skills for healthcare professionals (Clayton et al., 2008), but not yet common practice, as only $38 \%$ of cancer patients reported that their diagnosis was conveyed in an empathic manner (Spiegel et al., 2009). Compared to previous studies, it is remarkable how often participants in our focus-group study emphasized the involvement of other professionals (e.g., palliative care consultant teams and spiritual counselors) to help patients and physicians with this transition and with the reframing of hope. Such professionals have important functions: whereas palliative care consultant teams can advise physicians in such a way that they gain more hope and faith in the possibilities of palliative care, spiritual counselors can help patients and their families to cope with and give (spiritual) meaning to the end of life. As hope hasmany facets onwhich healthcare professionals cannot all be expert, referral to other professionals has also been recommended elsewhere (Olsman et al., 2014). Especially the Muslim participants in our focusgroup study emphasized the involvement of an imam in end-of-life communications. Aside from providing spiritual care, an imam or other professional with a Muslim background might facilitate clear communications among the patient, his/her family, and physicians at the end of life. Such an intermediary function may be even more important, as we found, in line with other studies (Ozdogan et al., 2004; 2006; Oksu“ zog `lu et al., 2006; de Graaff et al., 2010; 2012a; 2012b), that relatives of people with a Muslim 
Oosterveld-Vlug, M.G., Francke, A.L., Pasman, H.R., Onwuteaka-Philipsen, B.D. How should realism and hope be combined in physician-patient communication at the end of life? An online focus-group study among participants with and without a Muslim background. Palliative \& 1 Supportive Care: 2016

background are often quite influential in end-of-life communications and decisions and sometimes choose to not confront the patient with his/ her poor prognosis. This does not mean that physicians do not have to be open and honest with Muslim patients. Whereas previous studies found that one of the main concerns about good care expressed by Turkish and Moroccan families was "never having hope taken away" (de Graaff et al., 2010; 2012a), our findings present a more nuanced picture. When realistic information from amedical perspective is introduced in a culturally sensitive way (e.g., not by stating that a patient is incurably ill, but by informing the patient that the physician himself no longer has any available treatment options), hope can be maintained. This approach seemed acceptable to Muslims and was actually preferred by the participants in our focus-group study.

\section{LIMITATIONS AND METHODOLOGICAL CONSIDERATIONS.}

In our study, all participants had a close experience of receiving or providing care at the end of life, but they were not necessarily an incurably ill patient or healthcare professional themselves. Their responses should therefore be regarded as a combination of views on preferences for end-of-life communication and experiences, which might have contributed to our finding that healthcare professionals and Dutch patients (without a Muslim background) had remarkably similar ideas about what would be best practice. Furthermore, although we tried to recruit a study sample with diverse characteristics, one should bear in mind that only people with access to the internet and with sufficient computer skills could participate, meaning that frail older people and people with a low level of literacy weremost probably not included. In addition, we recruited people based on their cultural background (Muslim or not), but we did not take level of religiosity or education into account, which might also influence experiences with and preferences for realistic and hopeful information. A clear advantage of conducting focus groups online is that participants can react anonymously from any place at any time, thus enhancing the richness of their reactions. However, this method also has its limitations.

For example, participants reacted to each other's comments, but to a lesser extent than would have been expected in face-to-face focus groups. In addition, we noticed a decrease in the number of responses in all OFGs as the study period progressed and new themes and questions were posed. The number of responses in the OFG with Muslims stayed below that in other groups, even after motivating emails were sent by the organization through which participants were recruited.

Moreover, only 9 Muslim participants reacted at the discussion site, while 15 people agreed to participate in the focus group. It couldbe that conducting focus groups onlinewas not suitable for some of these participants.

Nevertheless, we were able to garner interesting responses from people with a Muslim background, who are known to be difficult to include in all types of studies (whether online or not).Further research is recommended, with a larger sample of Muslims, that would take account of the other factors that may influence preferences in terms of hope and realism.

\section{CONCLUSIONS.}

Realistic and hopeful information are not necessarily mutually exclusive and can even be combined when discussing diagnosis and prognosis at the end of life. To support the transition of patients and relatives from "hope for a cure" to "hope for a 
Oosterveld-Vlug, M.G., Francke, A.L., Pasman, H.R., Onwuteaka-Philipsen, B.D. How should realism and hope be combined in physician-patient communication at the end of life? An online focus-group study among participants with and without a Muslim background. Palliative \& Supportive Care: 2016

good death," realistic information can best be provided delicately and in a culturally sensitive way. This means that, when communicating with patients who are in the last phase of life, physicians and other healthcare professionals should be aware of individual, cultural, and religious diversity with respect to views on hope, and they should realize that some patients will never cease to hope for a cure. In their communications with Muslim patients, physicians would do best by being open and providing realistic information while at the same time paying close attention to the wording of their messages. Communication skills training as well as inculcating knowledge about cultural and religious diversity into medical educational programs could improve physician-patient communications at the end of life. The focus of future research should be whether or not patients who receive information in away that combines realism with hope and empathy have more favorable outcomes (e.g., increased awareness and understanding of their prognosis and satisfaction with consultations).

\section{ACKNOWLEDGMENTS.}

This study was supported by the Royal Dutch Medical Association (KNMG). We would like to thank all the participants in the focus-group discussions, as well as Yvonne Heijgele from NOOM and Agnes van Balkom from Unie KBO for their help in recruiting participants.

\section{REFERENCES.}

Back, A.L., Arnold, R.M. \& Quill, T.E. (2003). Hope for the best, and prepare for the worst. Annals of Internal Medicine, 138(5), 439-443. Available from http://annals.org/article. aspx?articleid=716134.

Benzein, E., Norberg, A. \& Saveman, B. (2001). The meaning of the lived experience of hope in patients with cancer in palliative home care. Palliative Medicine, 15(2), 117-126.

Boyatzis, R.E. (1998). Transforming qualitative information: Thematic analysis and code development. Thousand Oaks, CA: Sage.

Buiting, H.M., Rurup, M.L., Wijsbek, H., et al. (2011). Understanding provision of chemotherapy to patients with end stage cancer: Qualitative interview study. BMJ, 342, d1933. Available from https://www.ncbi.nlm.nih.gov/pmc/articles/PMC3070432/.

Chen, A.B., Cronin, A., Weeks, J.C., et al. (2013). Expectations about the effectiveness of radiation therapy among patients with incurable lung cancer. Journal of Clinical Oncology, 31(21), 2730-2735. Available from https:// www.ncbi.nlm.nih.gov/pmc/articles/PMC3709058/.

Clayton, J.M., Butow, P.N., Arnold, R.M., et al. (2005). Fostering coping and nurturing hope when discussing the future with terminally ill cancer patients and their caregivers.

Cancer, 103(9), 1965-1975. Available from http://onlinelibrary.wiley.com/doi/10.1002/cncr.21011/ full.

Clayton, J.M., Hancock, K., Parker, S., et al. (2008). Sustaining hope when communicating with terminally ill patients and their families: A systematic review. Psycho- Oncology, 17(8), 641-659.

Curtis, J.R.,Wenrich, M.D., Carline, J.D., et al. (2002). Patients' perspectives on physician skill in end-of-life care: Differences between patients with COPD, cancer and AIDS. Chest, 122(2), 356-362.

Curtis, J.R., Engelberg, R., Young, J.P., et al. (2008). An approach to understanding the interaction of hope and desire for explicit prognostic information among individuals with severe chronic obstructive pulmonary disease or advanced cancer. Journal of Palliative Medicine, 11(4), 610-620.

de Graaff, F.M., Francke, A.L., van den Muijsenbergh, M.E.T.C., et al. (2010). "Palliative care": A contradiction in terms? A qualitative study of cancer patients with a Turkish or Moroccan background, their relatives and care providers. BMC Palliative Care, 9, 19. Epub 
Oosterveld-Vlug, M.G., Francke, A.L., Pasman, H.R., Onwuteaka-Philipsen, B.D. How should realism and hope be combined in physician-patient communication at the end of life? An online focus-group study among participants with and without a Muslim background. Palliative \& Supportive Care: 2016

ahead of print Sep 10. Available from https://www.ncbi.nlm.nih.gov/pmc/articles/PMC2944252/.

de Graaff, F.M., Mistiaen, P., Deville', W.L., et al. (2012a). Perspectives on care and communication involving incurably ill Turkish and Moroccan patients, relatives and professionals: A systematic literature review. BMC Palliative Care, 11(1), 17. Available from http://dare.uva.nl/document/2/102630.

de Graaff, F.M., Francke, A.L., van den Muijsenbergh, M.E.T.C., et al. (2012b). Talking in triads: Communication with Turkish and Moroccan immigrants in the palliative phase of cancer. Journal of Clinical Nursing, 21(21-22), 3143-3152 de Haes, H.\&Koedoot, N. (2003). Patient-centered decision making in palliative cancer treatment: Aworld of paradoxes. Patient Education and Counseling, 50(1), 43-49.

Hagerty, R.G., Butow, P.N., Ellis, P.M., et al. (2005). Communicating with realism and hope: Incurable cancer patients' views on the disclosure of prognosis. Journal of Clinical Oncology, 23(6), 1278-1288. Available from http://jco.ascopubs.org/content/23/6/1278.long.

KNMG (Royal Dutch Medical Association), Stuurgroep Passende zorg in de laatste Levensfase (2015). Rapport: Niet alles wat kan, hoeft [Report: Not everything possible needs to be done] [in Dutch]. Utrecht, The Netherlands: KNMG.

Lin, H.R. \& Bauer-Wu, S.M. (2004). Psycho-spiritual wellbeing in patients with advanced cancer: An integrative review of the literature. Journal of Advanced Nursing, 44(1), 69-80.

Mattes, M.D. \& Sloane, M.A. (2015). Reflections on hope and its implications for end-of-life care. Journal of the American Geriatrics Society, 63(5), 993-996. Epub ahead of print May 4.

McClement, S.E. \& Chochinov, H.M. (2008). Hope in advanced cancer patients. European Journal of Cancer, 44(8), 1169-1174. Epub ahead of print Mar 21.

Oksu“" zog lu, B., Abali, H., Bakar, M., et al. (2006). Disclosure of cancer diagnosis to patients and their relatives in Turkey: Views of accompanying persons and influential factors in reaching those views. Tumori, 92(1), 62-66.

Olsman, E., Leget, C., Onwuteaka-Philipsen, B.D., et al. (2014). Should palliative care patients' hope be truthful, helpful or valuable? An interpretative synthesis of literature describing healthcare professionals' perspectives on hope of palliative care patients. Palliative Medicine, 28(1), 59-70. Epub ahead of print Apr 15, 2013.

Olsman, E., Willems, D.L. \& Leget, C. (2015). Solicitude: Balancing compassion and empowerment in a relational ethics of hope. An empirical-ethical study in palliative care. Medicine, Health Care, and Philosophy, 19(1), 11-20. Available from https://www.ncbi.nlm.nih.gov/ pmc/articles/PMC4805712/.

Olver, I.N. (2005). Bioethical implications of hope. In Interdisciplinary perspectives on hope. J. Elliott (ed.), pp. 241-256. New York: Nova Science.

Ozdogan, M., Samur,M., Bozcuk, H.S., et al. (2004). "Do not tell":What factors affect relatives' attitudes to honest disclosure of diagnosis to cancer patients? Supportive Care in Cancer, 12(7), 497-502. Epub ahead of print Apr 16.

Ozdogan, M., Samur, M., Artac, M., et al. (2006). Factors related to truth-telling practice of physicians treating patients with cancer in Turkey. Journal of Palliative Medicine, 9(5), $1114-1119$.

Pattison, N.A. \& Lee, C. (2011). Hope against hope in cancer at the end of life. Journal of Religion and Health, 50(3), 731-742. Epub ahead of print Jun 16, 2009.

Robinson, C.A. (2012). "Our best hope is a cure": Hope in the context of advance care planning. Palliative \& Supportive Care, 10(2), 75-82. Epub ahead of print Feb 24.

Rustoen, T. (1995). Hope and quality of life, two central issues for cancer patients: A theoretical analysis. Cancer Nursing, 8(5), 355-361.

Spiegel,W., Zidek, T., Maier, M., et al. (2009). Breaking bad news to cancer patients: Survey and analysis. Psycho-Oncology, 18(2), 179-186. Epub ahead of print Aug 1, 2008.

Tates, K., Zwaanswijk, M., Otten, R., et al. (2009). Online focus groups as a tool to collect data in hard-toinclude populations: Examples from paediatric oncology. BMC Medical Research Methodology, 9, 15. Available from https://www.ncbi.nlm.nih.gov/pmc/ar ticles/PMC2653071/. 
Oosterveld-Vlug, M.G., Francke, A.L., Pasman, H.R., Onwuteaka-Philipsen, B.D. How should realism and hope be combined in physician-patient communication at the end of life? An online focus-group study among participants with and without a Muslim background. Palliative \& 7 Supportive Care: 2016

van Vliet, L.M. (2013). Balancing explicit with general information and realism with hope: Communication at the transition to palliative breast cancer care. Doctoral dissertation. Utrecht, The Netherlands: Netherlands Institute for Health Services Research. van Vliet, L., Francke, A., Tomson, S., et al. (2013). When cure is no option: How explicit and hopeful information can be given? A qualitative study in breast cancer. Patient Education and Counseling, 90(3), 315-322. Epub ahead of print May 8, 2013.

Weeks, J.C., Catalano, P.J., Cronin, A., et al. (2012). Patients' expectations about effects of chemotherapy of advanced cancer. The New England Journal of Medicine, 367(17), 16161625. Available from https://www.ncbi.nlm.nih.gov/pmc/articles/PMC3613151/.

Zwaanswijk, M. \& van Dulmen, S. (2014). Advantages of asynchronous online focus groups and face-to-face focus groups as perceived by child, adolescent and adult participants: A survey study. BMC Research Notes, 7, 756.

\section{TABLES}

Table 1. Characteristics of participants

\begin{tabular}{|c|c|c|c|c|}
\hline Group & $\begin{array}{l}\text { Number and sex } \\
\text { of participants }\end{array}$ & $\begin{array}{l}\text { Age range } \\
\text { (mean) }\end{array}$ & Occupation $^{1}$ & Country of origin \\
\hline $\begin{array}{l}\text { (1) Patients, } \\
\text { older people, } \\
\text { relatives }\end{array}$ & $\begin{array}{l}13(6 \mathrm{M}, 7 \mathrm{~F}) \\
11(7 \mathrm{M}, 4 \mathrm{~F})\end{array}$ & $\begin{array}{l}49-80(66.1) \\
45-73(62.8)\end{array}$ & & $\begin{array}{l}12 \text { Netherlands, } 1 \text { Indonesia } \\
10 \text { Netherlands, } 1 \text { Indonesia }\end{array}$ \\
\hline \multirow[t]{2}{*}{$\begin{array}{l}\text { (2) Healthcare } \\
\text { professionals }\end{array}$} & $10(4 \mathrm{M}, 6 \mathrm{~F})$ & $27-68(52.0)$ & $\begin{array}{l}2 \text { elderly care physicians, GP, } \\
\text { oncologist, surgeon, nurse } \\
\text { working on cardiology, district } \\
\text { nurse, nurse working on } \\
\text { ambulance, chaplain, coordinator } \\
\text { of hospice }\end{array}$ & 10 Netherlands \\
\hline & $11(3 \mathrm{M}, 8 \mathrm{~F})$ & $24-72(51.9)$ & $\begin{array}{l}2 \text { elderly care physicians, oncologist, } \\
\text { district nurse, nurse working on } \\
\text { ambulance, chaplain, specialist } \\
\text { nurse working on neurology, } \\
\text { specialist nurse working in } \\
\text { hospice, certified nursing } \\
\text { assistant and registered nurse } \\
\text { working in long-term care } \\
\text { facilities, social worker }\end{array}$ & 10 Netherlands, 1 Indonesia \\
\hline (3) Muslims & $9(7 \mathrm{M}, 2 \mathrm{~F})$ & $31-66(51.7)$ & & $\begin{array}{l}3 \text { Turkey, } 2 \text { Morocco, } \\
1 \text { Afghanistan, } 1 \\
\text { Surinam, } 1 \text { Indonesia, } 1 \\
\text { Netherlands }^{2}\end{array}$ \\
\hline
\end{tabular}

${ }^{1}$ Only available for healthcare professionals.

${ }^{2}$ Converted to Islam at a later age. 
Oosterveld-Vlug, M.G., Francke, A.L., Pasman, H.R., Onwuteaka-Philipsen, B.D. How should realism and hope be combined in physician-patient communication at the end of life? An online focus-group study among participants with and without a Muslim background. Palliative \& Supportive Care: 2016

Table 2. Quotes from participants regarding a circle of hope

1. "Certainly sounds familiar-keeping going with treatments and trying out new things. I'm sure it's all done with the best possible intentions-hope keeps you alive, and without life there is no hope. So the patients and doctors have each other in a vicious circle."

(woman, 55-60 years, OFG patients, older people, relatives)

2. "All too often, the doctor and patient are fooling each other: I'll act as if I can extend your life, and you will act as if you believe it."

(man, 65-70 years, OFG healthcare professionals)

3. "If there's a $10 \%$ chance of a cure, most people will think and hope that they are one of that $10 \%$."

(woman, 45-50 years, OFG healthcare professionals)

4. "It's obvious, I guess, that the choice of whether or not to continue treatment is made by the patient. However, you often see that the patient's relatives are also pushing them to try this thing or the other. In situations like that, patients often don't have the strength to resist. Or ... they feel some kind of guilt towards their loved ones if they don't go for all the possibilities. It makes a very complex whole."

(woman, 65-70 years, OFG patients, older people, relatives)

5. "People who are sick hope that they'll get better and expect the doctor to help them. Many of them expect more than is actually possible and overestimate what the doctor can do. The doctor sees and feels that patient's hope and empathizes with them. Naturally enough, they're hoping that the proposed treatment will work, and if the patient cannot be cured, then at least that death will be postponed or that it can make the patient feel better. But the costsin terms of the quality of life- of undergoing treatment are often underestimated."

(woman, 55-60 years, OFG healthcare professionals)

6. "Muslims, just like other religious people, will indeed always keep looking for a cure. In fact, the Koran does say that many problems can only be solved with the help of science. That is why Muslims will try everything, together with their doctors. These kinds of things are also often discussed within the family."

(man, 55-60 years, OFG Muslims)

7. "If someone is a cancer patient and a Muslim, they can't choose not to be treated because that's tantamount to suicide, which is a real sin in Islam."

(woman, 40-45 years, OFG Muslims) 
Oosterveld-Vlug, M.G., Francke, A.L., Pasman, H.R., Onwuteaka-Philipsen, B.D. How should realism and hope be combined in physician-patient communication at the end of life? An online focus-group study among participants with and without a Muslim background. Palliative \& $\&$ Supportive Care: 2016

Table 3. Quotes from participants regarding the balance between hopeful and realistic information

8. “Telling someone there's no hope of a cure isn't quite the same as saying they will die. Caregivers should discuss clearly with their patients exactly what is wrong from the very beginning, using scans and so forth if necessary. And they should make clear that stopping the "cure" side doesn't mean that the "care" side disappears as well. ... If they [the patients] are taken seriously from the beginning, they can discuss with the doctor what is desirable, whether to continue with "curing" or to make sure that they feel comfortable."

(woman, 60-65 years, OFG healthcare professionals)

9. 'I don't think that caregivers should provide overly hopeful information that is perhaps not true at all. It's better to be realistic, although they don't have to tell the patient that they've only got so long to live. In our religion and culture, it's customary under such circumstances to say that the doctors will do their best to cure the patient and that the patient must never give up hope, because only God knows when someone will draw their last breath. In that case, doctors can say that there's not much more they can do than to offer pain relief-the patient and the family will understand that."

(woman, 40-45 years, OFG Muslims)

10. "A doctor has to find the right balance between being hopeful and staying realistic. My hematologist once said to me, when I had to undergo yet another stem cell transplant, 'I get people in my consulting room - not many, but I do get a few-whose leukemia is a thing of the past. They come for an outpatient checkup once every three months, and that's it." Those words meant a great deal to me during what was an extremely difficult time. Even so, they did not give me any false hope.... I've also been on the receiving end of a real slap in the face from the doctor. After the transplant, my immune system had started to get going again a tiny bit. It was possible that my immune system would not start up again and I would die. When the doctor said, This doesn't mean anything yet-it could be back to zero tomorrow'-my world collapsed around me. Something like 'This could be the start. It's pretty uncertain as yet; these very low figures do sometimes fall right away and the immune system doesn't really get started again.' You're saying the same thing, but it makes a world of difference to a patient. In short, I think that the information should be given realistically, but also at the same time with at least a spark of hope if that is possible."

(woman, 45-50 years, OFG patients, older people, relatives)

11. "My opinion is that we must give realistic information: that's our role, as doctors. That includes an appropriate level of hope. Not the hope of extending their lifespan forever, but the hope of making their time as good as possible, even in the final phase. That's a positive aspect, not a deficiency. A severe burden of treatment and an undignified end aren't what people hope for. I don't want them to go through that and hope they won't have to. Realism is a means. Realism can lead to acceptance and 'peace,' letting you choose what you really still want. People don't get that opportunity if the only hope you give them is based on wishful thinking."

(woman, 45-50 years, OFG healthcare professionals)

12. “It's certainly possible to give hope and be realistic: be honest and direct, so that everyone understands the situation. Then you can discuss the follow-on steps, making clear that they don't have to cope with the final process on their own and that they will have assistance in dealing with it. It is often about the fear of that process-take that fear away."

(man, 60-65 years, OFG patients, older people, relatives)

13. "When someone is incurably ill, the doctors treating them should tell this to the patient's relatives and not the patient themselves, although the patients often realize it as well. Although it is not usual to ask what the patient's wishes are for the final phase of life, it is possible to ask about it without using the term 'terminal.' The doctors treating them or other caregivers can ask the question. In Islamic cultures, this question is asked by the family and friends, so that they are still able to do something significant for the patient."

(woman, 40-45 years, OFG Muslims)

14. "Muslims always put their hope in Allah. But Allah also says that there is a cure for every illness on earth. Muslims therefore certainly do have faith in their treatments. So stopping treatment is difficult for a Muslim, too. There must always still be hope, although the information must be realistic. A doctor can say that a certain treatment is no longer beneficial and that they do not have any other treatment. But the doctor mustn't say that there is no other possibility of treatment. The patient can decide for themselves whether they go and look for a different treatment, abroad if necessary. If the doctor closes the door on that by saying that cure is no longer possible, then a great deal of hope may be lost. Openness in what the doctor thinks about the treatment is important. He has to be realistic and open, but not too dogmatic."

(man, 30-35 years, OFG Muslims) 
Oosterveld-Vlug, M.G., Francke, A.L., Pasman, H.R., Onwuteaka-Philipsen, B.D. How should realism and hope be combined in physician-patient communication at the end of life? An online focus-group study among participants with and without a Muslim background. Palliative \& 7 Supportive Care: 2016

Table 4. Quotes from participants regarding the shifting of hopes

15. 'I don't want to use the word 'hope' here-that has too many associations with a cure. I'd prefer to talk about care for a comfortable end: what are the possibilities for that? Pain control, physically, but also emotionally and psychologically being able to bring your life to a close: what things do you want to have done? Who do you want to talk to, and what about? Are we able to do anything that will help you and your nearest and dearest 'let go'? That can bring a sense of peace in the process, both for the person who is going to die and for the people around them." (woman, 70-75 years, OFG patients, older people, relatives)

16. "Another kind of hope can be the hope of 'dying well'-goals are adjusted, the perspective changes. In other words, saying farewell to loved ones with dignity and arranging practical matters such as talking through any conflicts. Values such as autonomy, solidarity, comfort, dignity, and love are very important in this. Spirituality in the sense of an existence hereafter can offer peace and support-something to hold onto."

(woman, 35-40 years, OFG healthcare professionals)

17. 'Maybe caregivers themselves should also have hope'-of being able to provide appropriate care, particularly when a cure is no longer a possibility. Training is important in this, of course, but so is the option of being able to ask specialists for advice. An advisory team can be available not only for consultations, but also for support for internal training. If these are good four-dimensional recommendations, then there will be hope for both the patient and the caregivers."

(man, 45-50 years, OFG healthcare professionals)

18. "I think involving an imam is important, because believing in a life after this earthly life is an important credo." (man, 65-70 years, OFG Muslims)

19. "I ask for special attention for the assistance given to ethnic minority patients and their families. They often do not appreciate an impending death being discussed. The patient's beliefs often oblige them to continue the struggle, and they will then have no confidence in a doctor who says that they no longer have any realistic treatment options. There is sometimes an imperative need then to be receiving treatment. In situations like these, it is a good idea to look for a confidential adviser who is familiar with the cultural background and ask them to act as the contact." (man, 60-65 years, OFG healthcare professionals) 